\title{
Bioactivity Screening of Marine and Terrestrial Derived Fungi From Antarctica
}

\section{Bulent Gozcelioglu}

Scientific and Technological Research Institution of Turkey, Ankara, Turkey

\section{A B S T R ACT}

\begin{abstract}
The Antarctic region is situated in the Southern Hemisphere. The weather in Antarctica can often change dramatically in a short span of time. Due to these sudden changes the organisms and microorganisms which live in Antarctica produce unique metabolites to survive. In the present trial, the marine derived fungi from Antarctica's coast were researched for their antimicrobial activity. The disk diffusion technique was used to determined antimicrobial activity of isolated marine-derived fungi extracts. According to the obtained results the Penicillium chrysogenum and P. crustosum extracts were shown higher antibacterial against Gram positive and Gram negative rather than other extracts. In conclusion, marine derived fungi from Antarctica region produce the structurally novel and interesting bioactive compounds. Some of these fungi species such as Penicillium species are known to produce antimicrobial metabolites, the results obtained in this study also showed that Penicillium species show higher antimicrobial activity than the other species.
\end{abstract}

\section{Keywords:}

Antarctica, Antimicrobial activity, Live sources-derived fungi.

\author{
Article History: \\ Received: 2021/01/08 \\ Accepted: 2021/03/08 \\ Online: $2021 / 03 / 31$
}

Correspondence to: Bulent Gozcelioglu, Scientific and Technological Research Institution of Turkey, 06420, Ankara, Turkey E-Mail: bulent.gozcelioglu@gmail.com

\section{INTRODUCTION}

$\mathrm{M}$ arine living organism as sponges, tunicates corals and algae are productive sources of biologically active compounds used in the cosmetic and pharmaceutical industries. In addition, marine microorganisms also are abundant microbial committee of marine ecosystem varying from coast to deep sea. The bioactive compounds which produce by marine derived microorganisms are still largely unexplored and unexploited [1]. Marine microorganisms have an enormous capacity to produce different metabolites to sense and respond to their stressful environment. Some of these metabolites used as a pharmaceutical agent in the intervention of various human diseases [2]. Marine microorganisms due to their spacious genetic, metabolite diversity and wide spectrum of bioactivities including antibacterial, antifungal [3], antidiabetic [4], anti-inflammatory [5], antiprotozoal [6], anti-tuberculosis [7], antiviral [8], antitumor, and cytotoxic activities [9] become an interesting source for researchers. In our on-going search for biologically active metabolites from marine microorganisms, some marine derived fungi were collected from oceans and regional seas around Antarctica. Marine microorganisms for surviving in the harsh environmental conditions of Antarctica must develop different strategy such as produce various metabolites which may have a bioactive potential [10]. In this study, nine marine derived fungi were isolated from different marine organisms. All isolated fungi were identified and tested for their antimicrobial activities.

\section{MATERIALS AND METHODS}

\section{General}

The sea salts were bought from Sigma Aldrich, sabouraud 4\% dextrose agar (SDA), mullerhintonbroth, sabourauddextrose broth andethyl acetate was purchased from Merck. Nutrient agar was prepared from Oxide. Millipore Membrane Filter (MA 01730, USA). Biospeedy ${ }^{\circ}$ Fungal Diversity Kit was prepared from Bioeksen Turkey.

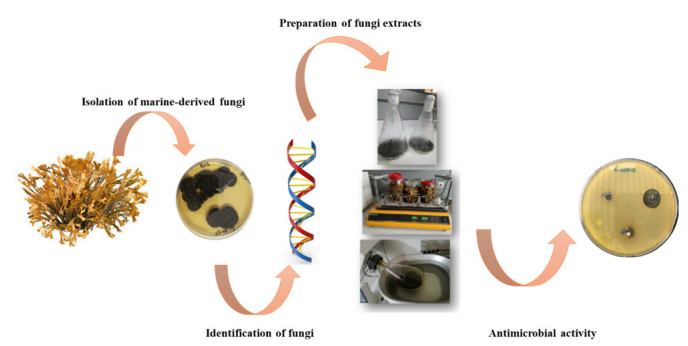

Figure 1. The process of isolation and bioactivity screening of marine derived fungi. 


\section{Isolation of Marine-Derived Fung}

Marine samples were collected oceans and regional seas around Antarctica in April 2018. Marine organisms were collected by scuba diving and then transferred to containers. The fungi isolation was process immediately to prevent the growth of bacteria in the culture medium. According to the Kjer et al. 2010, The samples were cut in $1 \times 1 \mathrm{~cm}$ and was cleaned down 3 multiplication with sterile water to remove superficies residues and for sterilization it was dunked in EtOH 70\% (Volume/Volume) for 60-120 seconds. Then the samples were dried and relocated to culture medium (SDA and artificial sea salt). The culture mediums were kept for $5-7$ daylight in $25^{\circ} \mathrm{C}$. The fungi samples were stored at $-70^{\circ} \mathrm{C}$ for further analysis [11].

\section{Identification of Fungi}

Fungi strains were identified by DNA isolation using a fungi DNA isolation and PCR-based Biospeedy ${ }^{\circ}$ fungi Diversity Kit. The sequences of the fungi amplicons were identified by the ABI Prism BigDye Terminator Cycle Sequencing Ready Reaction Kit using ABI Prism 377 DNA Sequencer [11, 12].

\section{Preparation of fungi extracts}

For preparative scale production of fungus extracts was carried out in $2 \mathrm{~L}$ erlenmeyer flasks contained sterilized rice and artificial sea salt medium, fungi strains were grown up in 4-6 weeks at $25^{\circ} \mathrm{C}$. The fungi strains were extracted by EtOAc by maceration, the obtained EtOAc extracts were dried under vacuum and kept at $4{ }^{\circ} \mathrm{C}$ until use [13].

\section{Antimicrobial activity}

The stock solutions of samples extract $(100 \mu \mathrm{g} / \mathrm{mL})$ were prepared in dimethyl sulphoxide. The solution was sterilized by Millipore Membrane Filter $(0.22 \mu \mathrm{m}$ pore size 47 mm diameter).

Staphylococcus epidermidis (ATCC 35984), Bacillus subtilis (ATCC 6633), Bacillus cereus (ATCC 14579) used as Gram-positive bacteria; Escherichia coli (ATCC 25922), Proteus vulgaris (ATCC 8427), and Enterobacter aerogene (ATCC 13048) used as Gram-negative bacteria strains. Furthermore, Candida albicans (ATCC 10231) and Candida tropicalis (ATCC 1308) used as yeast strains. All bacterial and yeast strains were employed for antimicrobial screening with taking CLSI recommendations into account by disk diffusion method for the antifungal and antibacterial activity of extracts [14]. The fresh grown bacteria and yeast strains were cultured in nutrient broth and sabouraud dextrose broth respectively. The culture mediums were set in a humid chamber and incubated at $35^{\circ} \mathrm{C}, 24$ hours for the bacteria and at $30^{\circ} \mathrm{C}, 48$ hours for yeasts. Transfer growth into broth and incubate broth for 18-hour until the visible turbidity is equal to the $0.5 \mathrm{McF}$ arland. Muller hinton agar was prepared and terile paper disks $(6 \mathrm{~mm})$ were set onto the inoculated agar surface and $50 \mu \mathrm{L}(100$ $\mu \mathrm{g} / \mathrm{mL}$ ) of each extract were added to the paper disk. The plates were incubated for $22 \mathrm{~h}$ at $37^{\circ} \mathrm{C}$. The results were obtained by measuring the inhibition zone diameter.

\section{RESULTS}

Marine species which listed in Table 1 were collected from different coasts of Antarctica. Nine fungi species were isolated and identified from marine samples. All isolated fungi strains are shown in Table 1 and Fig. 2. The fungi strains were isolated from algae, lichen, sponge and sediment samples. All the samples were collected from Antarctica region.

The EtOAc extracts of the isolated fungi were prepared. The antimicrobial activity of fungi extracts was determined by disk diffusion assay. The results were obtained by measuring from the center of the extract disk to a point on the circumference of the zone where a distinct edge is present. Antimicrobial values are reported in millimeters and shown in Table 2, Fig. 3 and 4.

Table 1. UTM Coordinates of Point Transect Locations

\begin{tabular}{ll}
\hline \multicolumn{1}{c}{ Origin } & \multicolumn{1}{c}{ Fungi species } \\
\hline Himantothallus grandifolius (Algae) & Penicillium chrysogenum \\
Desmarestia antarctica (Algae) & Penicillium crustosum \\
Gigartina skottsbergii (Algae) & Cladosporium sp. \\
Monostroma hariotii (Algae) & Botrytis sp. \\
Sediment & Ulocladium microsporum \\
Umbilicaria antarctica (Lichen) & Alternaria alternata \\
Anoxycalyx joubini(Sponge) & Aspergillus awamori \\
Usnea antarctica (Lichen) & Alternaria malorum \\
Usnea antarctica (Lichen) & Cladosporium malorum \\
\hline
\end{tabular}

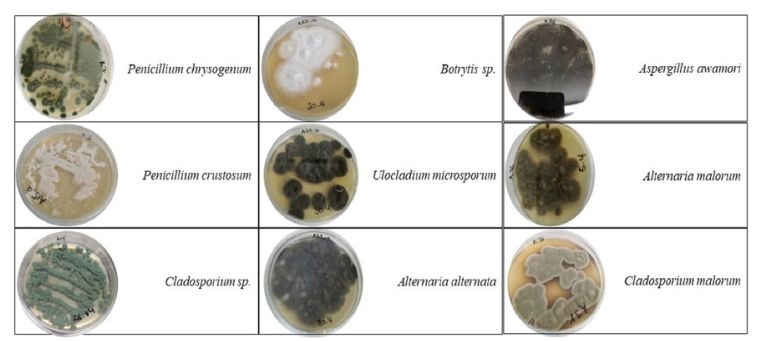

Figure 2. Obtained fungi strains from marine species 
Table 2. Antimicrobial activity of fungal strains from marine species

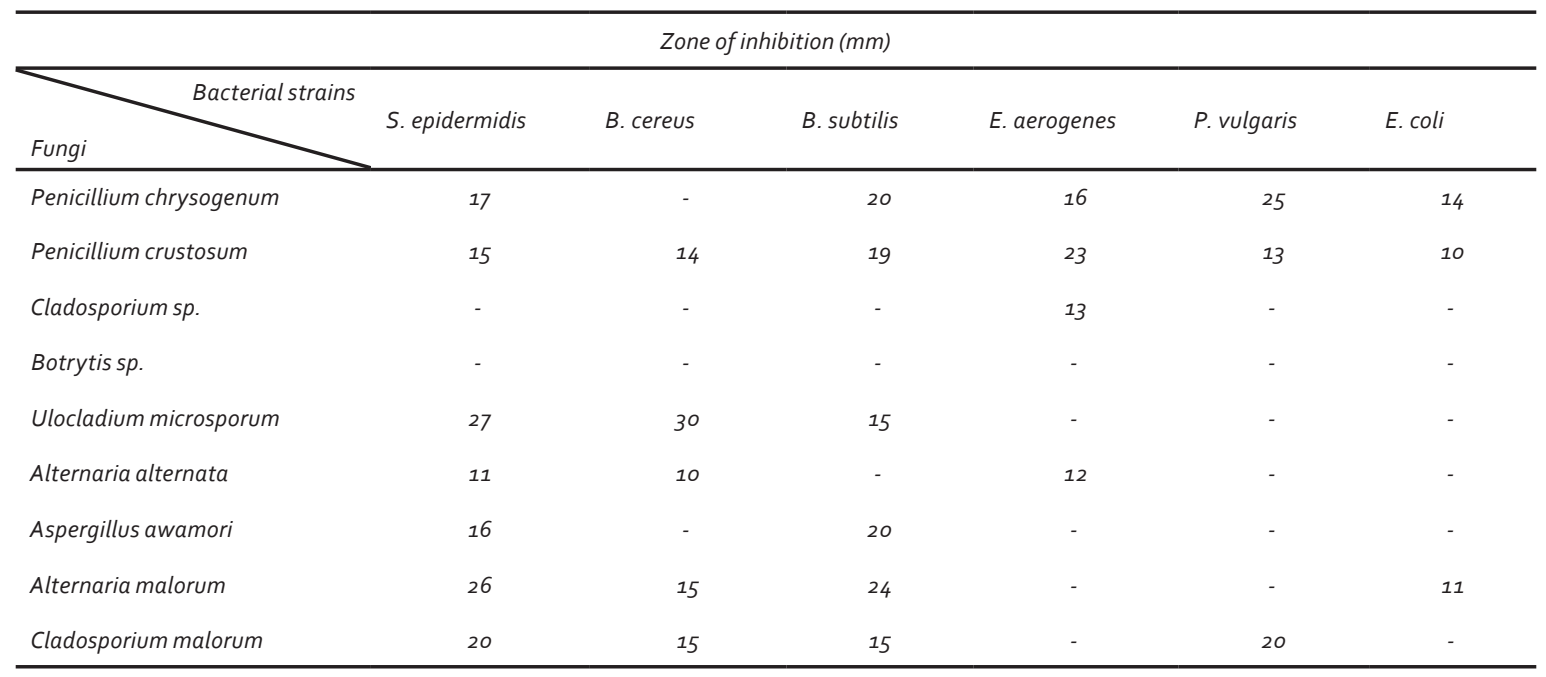

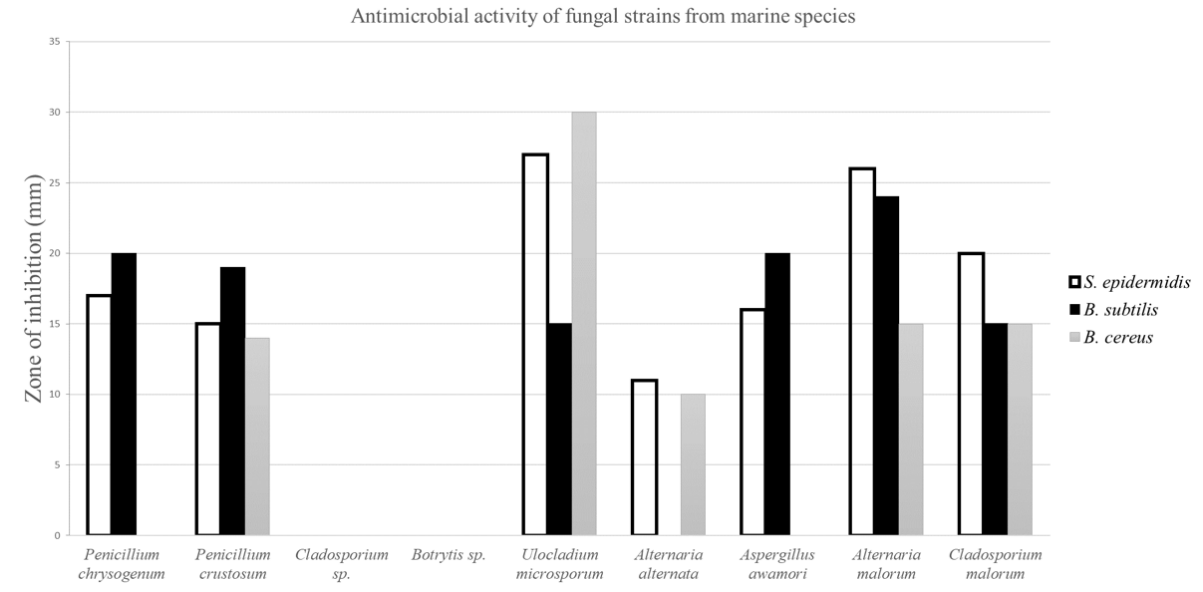

Figure 3. Antimicrobial activity of fungal strains against S. epidermidis, B. cereus, B. subtilis

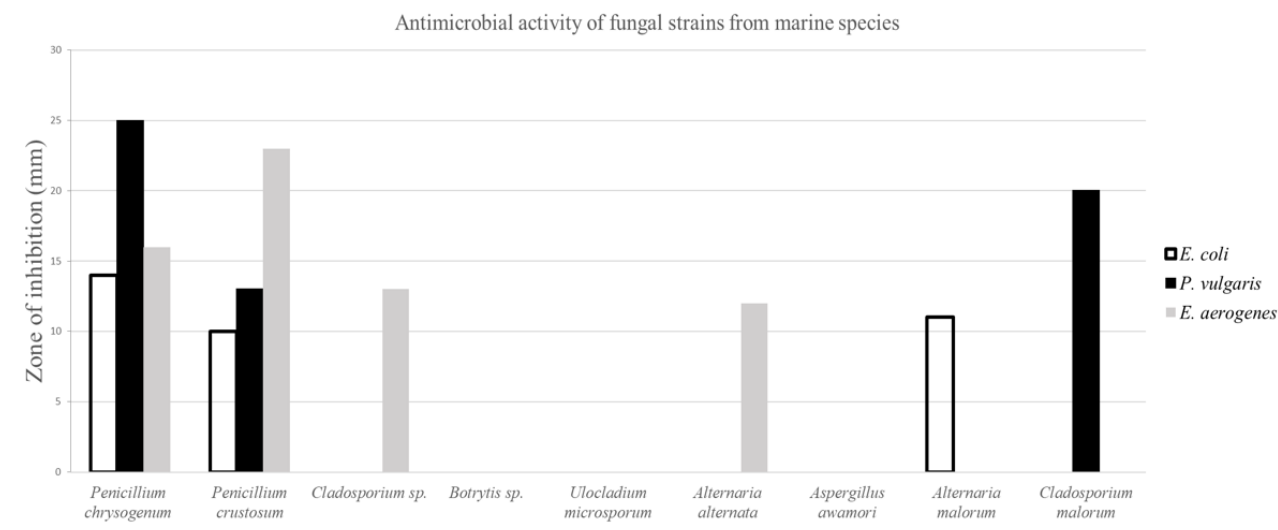

Figure 4. Antimicrobial activity of fungal strains against E.coli, P. vulgaris, E. aerogenes

\section{DISCUSSION}

Infectious diseases claim numerous lives worldwide every year, and many of these infections have been increased many-fold due to prolonged illness caused by widespread drug resistant pathogens. Every year, the drug-resistant pathogens are increasing, and finding new antimicrobial sources is considerable [15]. The study about marine organisms and marine derived microorganisms has been studied over the past few years. The marine derived microorganisms of Antarctica environments are an efficient field for unique bioactive secondary metabolites. Accor- 
ding to the harsh condition of Antarctica, marine derived fungi from this region produce the structurally novel and interesting bioactive compounds. As previous studies, so many biologically active compounds were isolated from unicellular bacteria, actinomycetes, fungi, lichens, mosses, bryozoans, cnidarians, echinoderms, molluscs, sponges and tunicates which collected from Antarctica region. Some of the isolated compounds were shown different activity such as cytotoxic, antioxidant, antimicrobial, anti-angiogenesis, neuroprotective, NF-kB inhibitory, antiparasitic and antiviral activities [16]. In this study some marine derived fungi from Antarctica coasts were investigated for their antimicrobial potential. According to the obtained results some of these fungi extracts displayed significant antimicrobial activity. According to the antimicrobial results, none of the fungi extracts did show antifungal activity against Candida albicans and Candida tropicalis. Also, Botrytis sp. was not active against tested bacterial strains. Penicillium crustosum extract was active against all tested bacterial strains. Among all extracts $U$. microsporum extract was shown highest activity against Gram positive strains rather than other obtained extracts. P. chrysogenum and P. crustosum were shown highest activity against Gram negative strains rather than other obtained extracts. Penicillium species are known to produce antimicrobial metabolites in previous studies, and the results obtained in this study also showed that Penicillium species show higher antimicrobial activity $[17,18]$. According to the previous studies and this work different fungi species show different antimicrobial activity, withal the same fungi species from different region also show dissimilar activity. This result is not uncommon, this steams from the secondary metabolites which produce by fungi. Numerous studies have shown that the Antarctic fungi have produced a wide range of bioactive metabolites and it is very important to discover these active metabolites and clear their activity $[19,20]$.

\section{CONCLUSION}

In conclusion, in this study, nine fungi were isolated from marine species collected from Antarctica coasts. This study is a preview study to discover more active fungi species and serves as a guide for future studies. Consequently, these extracts originated from the marine-derived fungi sources need further investigation with a view to identifying the active components that could be developed as potential drugs to be used against diseases threatening human health.

\section{ACKNOWLEDGEMENT}

I would like to thank Presidency of the Republic of Turkey, under the responsibility of the Ministry of Science,
Industry, and Technology of the Republic of Turkey, in coordination with the Istanbul Technical University Polar Research and Application and Research Centre.

\section{References}

1. Corinaldesi C, Barone G, Marcellini F, Dell'Anno A, Danovaro R. Marine Microbial-Derived Molecules and Their Potential Use in Cosmeceutical and Cosmetic Products. Marine Drugs 15 (2017) 118- 139.

2. Tripathi VC, Horam S, Singh A, Lata M, Reddy TJ, Arockiaraj J. Pasupuleti M. The diskovery of antioxidants in marine microorganisms and their protective effects on the hepatic cells from chemical-induced oxidative stress. Free Radical Research 54 (2020)150-161.

3. Karpiński TM. Marine Macrolides with Antibacterial and/or Antifungal Activity. Marine Drugs 17 (2019) 241- 265.

4. El-Hady FKA, Abdel-Aziz MS, Abdou AM, Shaker KH, Ibrahim LS, El-Shahid ZA. In vitro Anti-diabetic and Cytotoxic Effect of the Coral Derived Fungus (Emericella unguis 8429) on Human Colon, Liver, Breast and Cervical carcinoma cell lines. International Journal of Pharmaceutical Sciences Review and Research 27 (2014) 296-301.

5. $\mathrm{Xu} \mathrm{J,} \mathrm{Yi} \mathrm{M,} \mathrm{Ding} \mathrm{L,} \mathrm{He} \mathrm{S.} \mathrm{A} \mathrm{Review} \mathrm{of} \mathrm{Anti-Inflammatory}$ Compounds from Marine Fungi, 2000-2018. Marine Drugs 17 (2019) 636-660.

6. Pontius A, Krick A, Kehraus S, Brun R, König GM. Antiprotozoal activities of heterocyclic-substituted xanthones from the marinederived fungus Chaetomium sp. Journal of Natural Product 71 (2008)1579-1584.

7. Luo X, Zhou X, Lin X, Qin X, Zhang T, Wang J, Tu Z, Yang B, Liao S, Tian Y. Antituberculosis compounds from a deep-sea-derived fungus Aspergillus sp. Natural Product Research 31 (2017)19581962.

8. Moghadamtousi SZ, Nikzad S, Kadir HA, Abubakar S, Zandi K. Potential Antiviral Agents from Marine Fungi: An Overview. Marine Drugs13 (2015) 4520-4538.

9. Ramos AA, Preta-Sena M, Castro-Carvalho B, Dethoup T, Buttachon S, Kijjoa A, Rocha E. Potential of four marine-derived fungi extracts as anti-proliferative and cell death-inducing agents in seven human cancer cell lines. Asian Pacific Journal of Tropical Medicine 8(2015) 798-806.

10. Chavez R. Bioactive Compounds Produced by Antarctic Filamentous Fungi. Fungi of Antarctica (pp.265-283), 2019.

11. Gözcelioğlu B. Antioxidant and cytotoxic activity of three Turkish marine-derived fungi. Turkish Journal of Biochemistry. 44 (2019) 554-559.

12. Sun Y, Cai Y, Huse SM, Knight R, Farmerie WG, Mai V. A largescale benchmark study of existing algorithms for taxonomyindependent microbial community analysis. Brief Bioinform.13 (2011) 107- 121.

13. Kjer J, Debbab A, Aly AH, Proksch P. Methods for isolation of marine-derived endophytic fungi and their bioactive secondary products. Nature Protocols 5 (2010) 479-490.

14. CLSI. Methods for Dilution Antimicrobial Susceptibilit Tests f or Bacteria That Grow Aerobically; Approved St andard 9th Edition. CLSI document M07-A9. Wayne, PA: Clinical and Laboratory Standards Institute; 2012.

15. Mondol MA, Shin HJ. Antibacterial and antiyeast compounds from marine-derived bacteria. Marine Drugs. 12(2014) 2913-2921

16. Tian Y, Li YL, Zhao FC. Secondary Metabolites from Polar 
Organisms. Marine Drugs. 15(2017) 28-58.

17. Yang MH, Li TX, Wang Y, Liu RH, Luo J, Kong LY. Antimicrobial metabolites from the plant endophytic fungus Penicillium sp. Fitoterapia. 116 (2017) 72-76.

18. Gharaei-Fathabad E, Tajick-Ghanbary MA, Shahrokhi N Antimicrobial Properties of Penicillium Species Isolated from Agricultural Soils of Northern Iran. Research Journal of Toxins, 6 (2014) 1-7.

19. Henríquez M, Vergara K, Norambuena J, Beiza, A, Maza F, Ubilla
P, Araya I, Cha'vez R, San-Martín A, Darias J, Darias M, Vaca, I. Diversity of cultivable fungi associated with Antarctic marine sponges and screening for their antimicrobial, antitumoral and antioxidant potential. World Journal of Microbiology and Biotechnology, 30(2013) 65-76.

20. Albores S, Sanguiñedo P, Held BH, Cerdeiras MP, Blanchette RA. Biodiversity and antimicrobial activity of Antarctic fungi from the Fildes Peninsula, King George Island. Sydowia 70 (2018) 185-191. 